\title{
The clinical significance of lipopolysaccharide binding protein in hepatocellular carcinoma
}

\author{
QUAN-YU CAI ${ }^{1 *}$, JING-HUA JIANG $^{2 *}$, RI-MING JIN ${ }^{3}$, GUANG-ZHI JIN $^{4 * *}$ and NING-YANG JIA ${ }^{1^{* *}}$ \\ ${ }^{1}$ Department of Radiology; ${ }^{2}$ Tumor Immunology and Gene Therapy Center; \\ Departments of ${ }^{3}$ Hepatic Surgery I and ${ }^{4}$ Pathology, Eastern Hepatobiliary Surgery Hospital, Shanghai 200438, P.R. China
}

Received March 6, 2019; Accepted September 17, 2019

DOI: $10.3892 / \mathrm{ol} .2019 .11119$

\begin{abstract}
Lipopolysaccharide binding protein (LBP) has been reported to be associated with prognosis in colorectal carcinoma and renal cell carcinoma; however, the clinical significance of LBP in human primary hepatocellular carcinoma (HCC) is inconclusive. We aimed to investigate the clinical significance and prognostic value of LBP in human primary HCC. In the present study, 346 patients with HCC who underwent curative resection were retrospectively analyzed. LBP protein expression was evaluated using western blot analysis and immunohistochemistry. LBP scores collected from immunohistochemical analysis were obtained by multiplying staining intensity and the percentage of positive cells. An outcome-based best cutoff-point was calculated by X-tile software. Moreover, Kaplan-Meier curves and Cox regressions were used for prognosis evaluation. LBP was frequently overexpressed in HCC compared with that in peritumor tissues (five pairs by western blot analysis, $\mathrm{P}=0.0533 ; 77$ pairs by immunohistochemistry, $\mathrm{P}=0.0171$ ), and LBP expression was positively associated with tumor-node-metastasis stage and tumor differentiation. Patients who had high LBP expression had decreased overall survival and time to recurrence compared with patients with low LBP expression. Furthermore, patients who were both serum $\alpha$-fetoprotein positive and had high LBP expression had poor prognoses. Univariate and multivariate Cox analyses indicated that this combination was
\end{abstract}

Correspondence to: Professor Ning-Yang Jia, Department of Radiology, Eastern Hepatobiliary Surgery Hospital, 225 Changhai Road, Shanghai 200438, P.R. China

E-mail: ningyangjia@163.com

Professor Guang-Zhi Jin, Department of Pathology, Eastern Hepatobiliary Surgery Hospital, 225 Changhai Road, Shanghai 200438, P.R. China

E-mail: jgzhi@hotmail.com

\section{${ }^{* * * *}$ Contributed equally}

Key words: hepatocellular carcinoma, lipopolysaccharide binding protein, $\alpha$ fetoprotein, immunohistochemistry, overall survival, time to recurrence an independent prognostic factor [overall survival: Hazard ratio (HR), 1.458; 95\% confidence interval (CI), 1.158-1.837; $\mathrm{P}=0.001$; time to recurrence: $\mathrm{HR}, 1.382 ; 95 \% \mathrm{Cl}, 1.124-1.700$; $\mathrm{P}=0.002]$. In conclusion, LBP is highly expressed in HCC, and high LBP expression combined with serum $\alpha$-fetoprotein may predict poor outcomes in patients with $\mathrm{HCC}$ following curative resection.

\section{Introduction}

Hepatocellular carcinoma (HCC) is the most common primary malignancy of the liver (1) and the fourth leading cause of cancer-related deaths in China (2). HCC incidence rates are highest in Eastern Asia and sub-Saharan Africa, but its prevalence is rapidly increasing in Western countries; for instance, in the United States, the incidence rate of HCC has increased from $\sim 3 \%$ in 1980 to $17 \%$ in 2012 (3). For early-stage HCC, surgical resection resulted in improved overall survival (OS) rates compared with local ablation therapy (LAT) or locoregional therapy (LRT) (4,5). However, recurrence rates after surgery are $40-80 \%$ within 5 years, making recurrence the leading cause of postoperative death among patients with HCC (6-8). Although many studies have reported prognostic markers for HCC, such as Capn4 (9), PEBP1 (10), CD24 (11) and EZH2 (12), the accuracy and clinical application of these markers are still limited. Therefore, developing novel effective biomarkers to classify patients with high risk of death or recurrence will assist clinicians to select the best therapeutic strategies for patients with HCC and provide personalized therapy according to the predicted risk of survival or recurrence (13).

Lipopolysaccharide binding protein (LBP) is a serum protein that is synthesized in the liver and involved in the recognition, binding, and transport of the bacterial cell wall compound lipopolysaccharide (LPS)/endotoxin $(14,15)$, which is a cell wall component of Gram-negative bacteria that plays a crucial role in aggravating $\mathrm{HCC}(16,17)$. LBP is commonly elevated in the liver and systemic circulation in patients with chronic liver diseases due to the increased intestinal permeability and bacterial translocation $(18,19)$. LBP has also been reported to be involved in the pathogenesis of sepsis (20). The increased research into LBPs has led to an appreciation of the diagnostic value of infection in patients with cancer with febrile neutropenia (21) and its prognostic value in serum 
and tissue levels in colorectal carcinoma (22) and renal cell carcinoma (23). However, the expression pattern and prognostic value of LBP in HCC remains unclear. To address this question, western blot analysis and immunohistochemistry (IHC) were used to evaluate LBP expression in patients with HCC following surgery, and then retrospectively explore its prognostic value in this patient population.

\section{Materials and methods}

Patients, specimens, and follow-up. For the present study, 346 formalin-fixed paraffin-embedded (FFPE) HCC specimens $(10 \%$ neutral formaldehyde solution at room temperature for 12-24 h) were retrospectively obtained from patients (age, 22-77 years; male, $n=302$ and female, $n=43$ ) who underwent surgical resection between December 2005 and December 2008 at the Eastern Hepatobiliary Surgery Hospital (EHBH). Among them, 77 pairs of tumors and adjacent non-tumor liver tissues (peritumor liver tissues, distance between tumors and non-tumor tissue at least $2 \mathrm{~cm}$ ) were used to explore LBP expression. Additionally, LBP expression was explored in low-grade dysplastic nodules (LGDN, $\mathrm{n}=15$ ), high-grade dysplastic nodules (HGDN, $\mathrm{n}=12$ ) and well-differentiated HCC (well-HCC, $\mathrm{n}=18$ ) (Table S1) in specimens obtained from patients (age, 7-79 years; male, $\mathrm{n}=31$ and female, $\mathrm{n}=14$ ) who underwent curative resection between January 2005 and December 2011 at the EHBH. For western blot analyses, five paired HCC and peritumor liver tissues (age, 28-84; male, $n=3$ and female, $n=2$ ) were obtained from $\mathrm{EHBH}$ in July 2017 and frozen at $-80^{\circ} \mathrm{C}$. For diagnosis, hematoxylin and eosin (H\&E)-stained sections were reviewed by two experienced hepatopathologists. H\&E staining was performed at room temperature and observed under a Leica DM IRE2 microscope (Leica Microsystems Imaging Solutions Ltd). Diagnoses of HCC was based on the criteria proposed by the World Health Organization (WHO) (24). The inclusion criteria of the patients for the present study were: i) A diagnosis of HCC consistent with histological diagnostic criteria of the World Health Organization; ii) no pre-operative anticancer treatment; and iii) No evidence of extrahepatic metastases (25). LGDN, HGDN and well-HCC was diagnosed based on previously described criteria (26). Briefly, hepatocytes in LGDN appear normal or exhibit minimal nuclear atypia and a slightly increased nucleus to cytoplasm $(\mathrm{N}: \mathrm{C})$ ratio, but mitotic figures are absent. HGDN is characterized by cytologic and/or structural atypia, but insufficient for a diagnosis of well-HCC. Well-HCC was diagnosed based on the following criteria: i) Increased cell density (more than twice compared with that of the surrounding liver) with an increased $\mathrm{N}: \mathrm{C}$ ratio; ii) irregular thin trabecular pattern of growth; iii) pseudoglandular structures; iv) fat distribution change; v) unpaired arteries; vi) intratumoral portal tracts; and vii) stromal invasion.

Each patient provided written informed consent, and the institutional review board of EHBH approved the present study. Overall survival (OS) time was defined as the interval between surgery and death or the last follow-up. Time to recurrence (TTR) was measured from the date of tumor resection to the date of detecting a tumor recurrence or the last follow-up (27). Patients were followed-up at the clinic every 3 months during the first year after surgery and every 6 months thereafter until
December 2013. Follow-up observations were performed by two physicians who were blinded to the study. Abdomen ultrasonography, chest X-ray and a test for serum $\alpha$ fetoprotein (AFP, AFP (+), serum AFP $>20 \mathrm{ng} / \mathrm{ml}$; AFP (-), serum AFP $\leq 20 \mathrm{ng} / \mathrm{ml}$ ) concentration were used to monitor the patients every 3 months during the first year after surgery and every 3-6 months thereafter. Serum AFP were determined on Roche Modular E170 immunology analyzer (Roche Diagnostics $\mathrm{GmbH}$ ) with serum AFP test kits (cat. no. 11731327; Roche Diagnostics $\mathrm{GmbH}$ ). Magnetic resonance imaging or computed tomography scanning of the abdomen were performed every 6 months or immediately after a recurrence was suspected (28).

Protein extraction and western blot analysis. Western blot analysis was performed according to a previous study (29). Briefly, tissue samples were homogenized in a RIPA buffer (Qiagen, Inc.) supplemented with a cocktail of proteinase inhibitors and with a cocktail of phosphatase inhibitors (both Roche Diagnostics). Protein concentrations were determined using a bicinchoninic acid kit (Pierce; Thermo Fisher Scientific, Inc.). Proteins $(20 \mu \mathrm{g} / \mathrm{lane})$ were separated using 10\% SDS-PAGE and transferred to nitrocellulose membranes (Bio-Rad Laboratories, Inc.). After blocking with $5 \%$ bovine serum albumin/PBS at room temperature for $1 \mathrm{~h}$, the membranes were incubated with primary LBP antibody (anti-LBP antibody; 1:1,000 dilution; cat. no. ab169776; Abcam) and $\beta$-actin (1:1,000 dilution; cat. no. 4970; Cell Signaling Technology, Inc.) overnight at $4^{\circ} \mathrm{C}$. After washing with Tween-20 (0.05\%) in PBS, the membranes were incubated with horseradish peroxidase-conjugated goat anti-rabbit IgG antibody $(1: 2,000$ dilution; cat. no. 7074; Cell Signaling Technology, Inc.) for $1 \mathrm{~h}$ at room temperature. LBP and $\beta$-actin were detected using ECL development solution (Pierce; Thermo Fisher Scientific, Inc.). LBP and $\beta$-actin expression levels were determined using Quantity One v4.6.2 software (Bio-Rad Laboratories, Inc.). $\beta$-actin was used as a loading control.

Tissue microarray (TMA), IHC and scoring. For tissue microarray construction, $\mathrm{H} \& \mathrm{E}$-stained samples were reviewed by two experienced pathologists and the representative cores were pre-marked in the paraffin blocks. A tissue cylinder with a diameter of $1.5 \mathrm{~mm}$ was punched using a Manual Tissue Microarrayer (Unitma Co., Ltd.) from the marked area of each block and incorporated into a recipient paraffin block. Sections $(4-\mu \mathrm{m})$ were then placed on slides pre-coated with 3-aminopropyltriethoxysilane. Paraffin sections were deparaffinized with xylene and rehydrated through decreasing concentrations of ethanol $(100,95$, and $85 \%$ for 5 min each) at room temperature. Antigens were retrieved using microwave irradiation for $5 \mathrm{~min}$ in citric acid buffer $\left(\mathrm{pH} \mathrm{6.0)}\right.$ ) at $100^{\circ} \mathrm{C}$, and slides were then cooled at room temperature for $120 \mathrm{~min}$, according to the protocol reported by Jin et al (30) with minor modifications. The slides were incubated with $3 \% \mathrm{H}_{2} \mathrm{O}_{2}$ /phosphate-buffered saline to block endogenous peroxidase activity, and then non-specific binding sites were blocked using $100 \%$ goat serum (Beyotime Institute of Biotechnology) for $1 \mathrm{~h}$ at room temperature. Primary anti-LBP antibody (1:200 dilution; cat. no. HPA001508; Sigma-Aldrich; Merck KGaA) was used for IHC. Tissue antigens were detected with an EnVision detection kit (cat. no. GK500705; Gene Tech Biotechnology, 
A

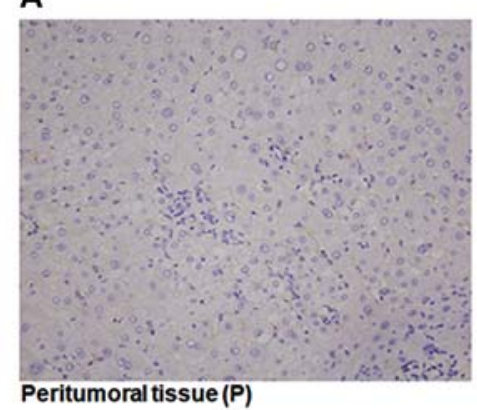

D

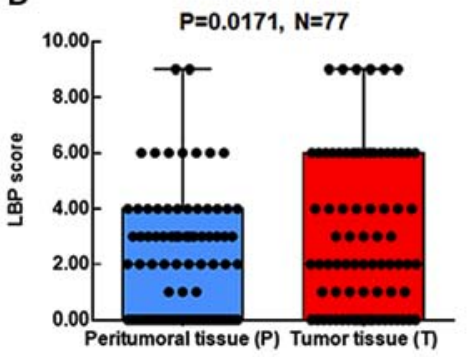

B

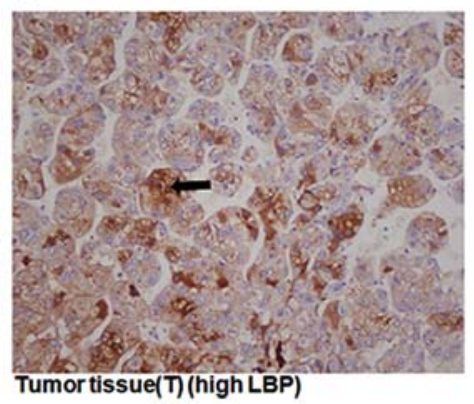

E

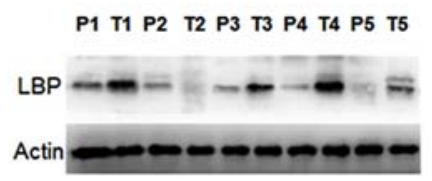

C

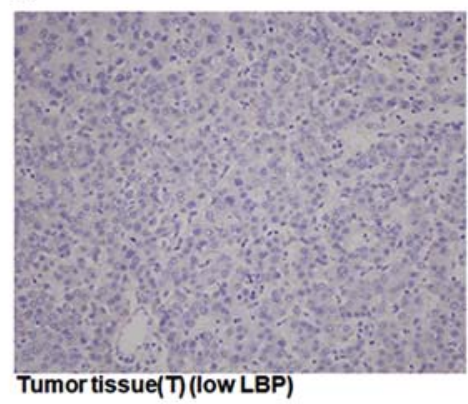

F

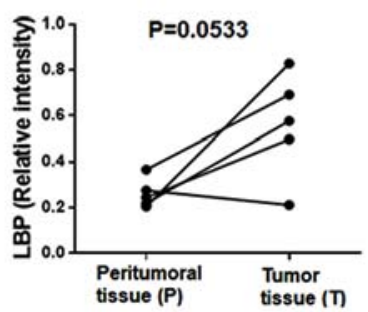

Figure 1. LBP expression levels in HCC and paired peritumor liver tissues. (A) Low LBP expression in paired peritumor liver tissue. (B) High LBP expression in HCC tissue. (C) Low LBP expression in HCC tissue (x200). (D) LBP levels were significantly decreased in paired peritumor liver tissue compared with that in HCC tissues ( $\mathrm{n}=77 ; \mathrm{P}=0.0171$; paired $\mathrm{t}$ test). (E) LBP expression was detected using western blot analysis in five paired peritumor tissues and HCC tissues. (F) Quantitation of LBP expression levels from western blot analyses showed that LBP expressions exhibited a trend for reduction in HCC tissues compared with paired peritumor liver tissues ( $\mathrm{P}=0.0533$; paired t-test). Arrow indicates cytosolic LBP expression. P, peritumor tissue; $\mathrm{T}$, tumor tissue; LBP, lipopolysaccharide binding protein; HCC, hepatocellular carcinoma.

Co., Ltd.). Counterstaining with Hematoxylin was performed for $5 \mathrm{~min}$ at room temperature and observed using a Leica DM IRE2 light microscope. Negative control slides were created for all assays and consisted of omitting primary antibodies.

For semi-quantitative evaluation of LBP from IHC, scoring was performed as follows: Staining intensity was first scored as 0 , negative; 1 weak; 2 , moderate; 3 , high, and then the percentage of positive cells was scored as $0,0 \%$ positive; 1 , $1-10 \%$ positive; $2,11-50 \%$ positive; and $3,>50 \%$ positive. A final score for each sample was obtained by multiplying the scores for staining intensity and percentage of positive cells scores to obtain LBP scores in HCC tissues.

Statistical analysis. Optimal LBP cut-off point for survival analysis was obtained by X-tile (version 3.6.1; Rimm Lab; Yale School of Medicine) as previously reported by Camp et al (31). LBP expression level in HCC and paired peritumor tissues were analyzed using paired t-test. LBP expression level between more than two groups of TNM, tumor differentiation and tumor grade (based on the pathological diagnosis report) were analyzed using one-way ANOVA and least significant difference post-hoc test for multiple comparisons. $\chi^{2}$ tests were used to compare qualitative variables. A cut-off point derived from 346 cases using The Mantel Cox log-rank test on X-tile was used to determine the statistical significance of the association between LBP expression and patient survival. SPSS standard version 13.0 (SPSS Inc.) was used to determine associations between variables, univariate survival analysis, and multiple Cox proportional hazards regression (forward, conditional likelihood ratio). $\mathrm{P}<0.05$ was considered to indicate a statistically significant difference.

\section{Results}

LBP is expressed in tumor tissues. To investigate LBP expression in patients with HCC, 346 paraffin blocks from patients with HCC were used to determine LBP expression as scores. IHC results demonstrated that LBP was primarily cytosolic. As shown in Fig. 1, LBP was rarely expressed in peritumor liver tissues (Fig. 1A), but frequently overexpressed in HCC tissues (Fig. 1B); some HCC tissues were negative for LBP (Fig. 1C). IHC results of 77 paired tumor tissues and peritumor liver tissues showed that LBP was highly expressed in tumor tissues (Fig. 1D; $\mathrm{P}=0.0171$ ).

LBP scores in peritumor tissues were 0,27 cases; 1 , 3 cases; 2, 10 cases; 3 , 16 cases; 4,12 cases; 6,7 cases, and 9, 2 cases. In tumor tissues the scores were 0,20 cases; 1,7 cases; 2, 13 cases; 3,5 cases; 4, 8 cases; 6,18 cases, and 9, 6 cases. For further confirmation, LBP expression was analyzed in five paired tumor and peritumor tissues using western blot analysis. As presented in Fig. 1E and F, due to the very low number of samples ( $\mathrm{n}=5$ pairs), no significant differences were observed between tumor tissues and peritumor liver tissues, although there was a trend for high LBP in tumor tissues $(\mathrm{P}=0.0533)$. Taken together, these results indicate that LBP is highly expressed in tumor tissues compared with that in peritumor liver tissues.

Clinicopathologicalfeatures of patients with HCC. Subsequently, univariate and multivariate Cox analyses were used to determine the prognostic significance of LBP and the clinicopathological parameters in the $346 \mathrm{HCC}$ cases (Table I). Univariate analysis showed that serum AFP $(\mathrm{P}=0.001)$, liver cirrhosis $(\mathrm{P}=0.006)$, 
Table I. Univariate and multivariate analyses of factors associated with OS and TTR in patients with hepatocellular carcinoma.

\begin{tabular}{|c|c|c|c|c|c|c|c|c|}
\hline \multirow[b]{3}{*}{ Clinicopathological factors } & \multicolumn{4}{|c|}{ OS } & \multicolumn{4}{|c|}{ TTR } \\
\hline & \multirow{2}{*}{$\frac{\text { Univariate }}{\text { P-value }}$} & \multicolumn{3}{|c|}{ Multivariate } & \multirow{2}{*}{$\frac{\text { Univariate }}{\text { P-value }}$} & \multicolumn{3}{|c|}{ Multivariate } \\
\hline & & HR & $95 \% \mathrm{Cl}$ & P-value & & HR & $95 \% \mathrm{Cl}$ & P-value \\
\hline Sex (male vs. female) & 0.665 & & & & 0.611 & & & \\
\hline Age, years ( $\leq 50$ vs. $>50)$ & 0.988 & & & & 0.947 & & & \\
\hline HBsAg (positive vs. negative) & 0.148 & & & & 0.107 & & & \\
\hline Serum AFP, ng/ml ( $\leq 20$ vs. $>20)$ & $0.001^{\mathrm{a}}$ & & & & $0.003^{\mathrm{a}}$ & & & \\
\hline Liver cirrhosis (yes vs. no) & $0.006^{\mathrm{a}}$ & 1.550 & $1.060-2.268$ & $0.024^{\mathrm{a}}$ & $<0.001^{\mathrm{a}}$ & 1.680 & $1.191-2.369$ & $0.003^{\mathrm{a}}$ \\
\hline TNM (I vs. II vs. III-IV) & $<0.001^{\mathrm{a}}$ & 1.514 & $1.188-1.929$ & $0.001^{\mathrm{a}}$ & $<0.001^{\mathrm{a}}$ & & & \\
\hline Child-Pugh (A vs. B) & 0.251 & & & & 0.266 & & & \\
\hline Tumor size, $\mathrm{cm}(\leq 5$ vs. $>5)$ & $<0.001^{\mathrm{a}}$ & 1.671 & $1.192-2.343$ & $0.003^{\mathrm{a}}$ & $<0.001^{\mathrm{a}}$ & 1.564 & $1.181-2.071$ & $0.002^{\mathrm{a}}$ \\
\hline Tumor number (single vs. multiple) & $<0.001^{\mathrm{a}}$ & & & & $<0.000^{\mathrm{a}}$ & 1.950 & $1.437-2.646$ & $<0.001^{\mathrm{a}}$ \\
\hline $\begin{array}{l}\text { Tumor differentiation (well vs. } \\
\text { moderate vs. poor) }\end{array}$ & $0.012^{\mathrm{a}}$ & & & & $0.014^{\mathrm{a}}$ & & & \\
\hline Vascular invasion (no vs. yes) & $0.004^{\mathrm{a}}$ & & & & $0.019^{\mathrm{a}}$ & & & \\
\hline LBP (low vs. high) & $0.008^{\mathrm{a}}$ & & & & $0.002^{\mathrm{a}}$ & & & \\
\hline $\begin{array}{l}\text { LBP/AFP [LBP low/AFP (-) vs. LBP } \\
\text { high/AFP (-) or LBP low/AFP (+) vs. } \\
\text { AFP (+) and LBP high] }\end{array}$ & $<0.001^{\mathrm{a}}$ & 1.458 & $1.158-1.837$ & $0.001^{\mathrm{a}}$ & $<0.001^{\mathrm{a}}$ & 1.382 & $1.124-1.700$ & $0.002^{\mathrm{a}}$ \\
\hline
\end{tabular}

${ }^{a} \mathrm{P}<0.05$. HBsAg, hepatitis B surface antigen; AFP, $\alpha$-fetoprotein; LBP, lipopolysaccharide binding protein; OS, overall survival; TTR, time to recurrence.

tumor-node-metastasis $(\mathrm{TNM})$ stage $(\mathrm{P}<0.0001)$, tumor size $(\mathrm{P}<0.0001)$, tumor number $(\mathrm{P}<0.0001)$, tumor differentiation $(\mathrm{P}=0.012)$, vascular invasion $(\mathrm{P}=0.004)$, LBP $(\mathrm{P}=0.008)$, and the LBP/serum AFP combination $(\mathrm{P}<0.0001)$ were significant prognostic factors for OS time. Similarly, serum AFP $(\mathrm{P}=0.003)$, liver cirrhosis $(\mathrm{P}<0.0001)$, TNM stage $(\mathrm{P}<0.0001)$, tumor size $(\mathrm{P}<0.0001)$, tumor number $(\mathrm{P}<0.0001)$, tumor differentiation ( $\mathrm{P}=0.014)$, vascular invasion $(\mathrm{P}=0.019)$, LBP $(\mathrm{P}=0.002)$, and the LBP/serum AFP combination $(\mathrm{P}<0.0001)$ were significant prognostic factors for TTR using univariate analysis. Furthermore, multivariate Cox analyses showed that, liver cirrhosis (HR,1.550; 95\% Cl, 1.060-2.268; P=0.024), TNM (HR, $1.514 ; 95 \% \mathrm{Cl} 1.188-1.929 ; \mathrm{P}=0.001)$, tumor size (HR, 1.671; $95 \%$ $\mathrm{Cl}, 1.192-2.343 ; \mathrm{P}=0.003)$, and the $\mathrm{LBP} /$ serum AFP combination (HR, 1.458; 95\% Cl, 1.158-1.837, $\mathrm{P}=0.001$ ) were independent prognostic factors for OS time. Liver cirrhosis (HR, 1.680; 95\% Cl, 1.191-2.369; $\mathrm{P}=0.003)$, tumor size (HR, 1.564; $95 \%$ $\mathrm{Cl}, 1.181-2.071 ; \mathrm{P}=0.002)$, tumor number $(\mathrm{HR}, 1.950 ; 95 \% \mathrm{Cl}$, 1.437-2.646; $\mathrm{P}<0.0001)$, and the $\mathrm{LBP} /$ serum AFP combination (HR, 1.382; 95\% Cl, 1.124-1.700; $\mathrm{P}=0.002$ ) were also independent prognostic factors for TTR. While there are many parameters associated with outcomes in patients with HCC, including LBP, our results showed that the combination of LBP and serum AFP is a novel valuable prognostic factor for OS time and TTR.

Prognostic value of LBP expression in patients with HCC. Kaplan-Meier curves were used to further determine the association between LBP score and prognosis. LBP scores in HCC tissues ranged from 0 to $9,40.7 \%$ (141/346) were $0,59.3 \%$ (205/346) were 1-9. X-tile analysis of 346 cases showed that the best cut-off point for survival analysis was 2 . Thus, if an IHC score of HCC tissue was $\leq 2$, the patient was classified as low-LBP; if the score was $>2$, the patients was classified as LBP-high. As shown in Fig. 2, OS time and TTR were significantly worse $(\mathrm{P}=0.007$ and $\mathrm{P}=0.002$, respectively) in the high LBP expression group $(n=113)$ compared with that in the LBP-low expression group $(n=233)$. Probability of post-operative survival demonstrated that the mean OS time for patients with $\mathrm{HCC}$ with high LBP levels was 41 months compared with 58 months for those with low LBP expression (Fig. 2A). The mean TTR for patients with HCC with high LBP levels was 29.1 months; for those with high LBP levels, it was 42.2 months (Fig. 2B). The representative LBP expression for shortest the OS time and TTR, and longest OS time and TTR is shown in Fig. S1. Furthermore, the 346 patients with HCC were classified into three groups according to LBP expression and serum AFP status: i) Group I, AFP (+) and LBP high (n=80); ii) group II, AFP (+)/LBP-low or AFP (-)/LBP-high $(\mathrm{n}=186)$; and iii) group III, AFP (-)/LBP-low $(n=80)$. Kaplan-Meier analysis demonstrated that patients in group I (AFP (+)/LBP-high) had the shortest OS time (mean, 35.4 months) and TTR (mean, 25.0 months), whereas patients in group III had the longest OS time (mean, 69.6 months) and TTR (mean, 50.3 months) (Fig. 2C and D).

LBP expression in aggressive tumor tissues. The $\chi^{2}$ test was used to identify associations with LBP expression with different variables. First, the associations between clinicopathological variables and LBP expression in patients with HCC $(n=346)$ were investigated. The results showed that LBP expression in HCC tissues was associated with TNM stage $(\mathrm{P}=0.035)$ and 

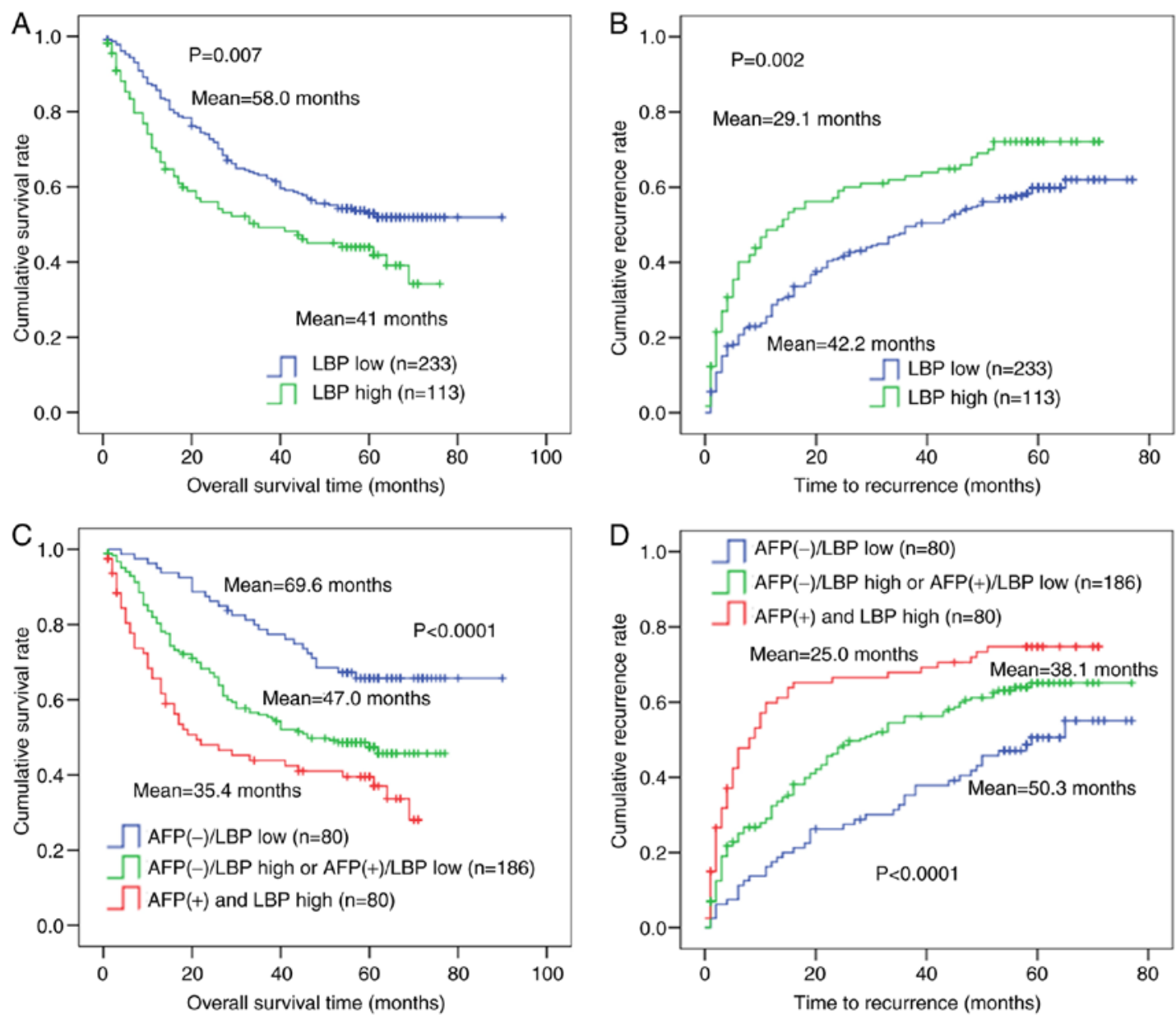

Figure 2. Kaplan-Meier curves for OS time and TTR in patients with HCC. (A) Probability of post-operative survival showed that the mean OS time for patients with HCC with high LBP levels was 41 months compared with 58 months for those with low LBP expression. (B) The mean TTR for patients with HCC with high LBP levels was 29.1 months; for those with high LBP levels, it was 42.2 months. Patients with HCC and serum AFP (+)/LBP high expression had poor (C) OS time and (D) TTR compared with that in patients with AFP (-)/LBP-low; AFP (-)/LBP high, or AFP (+)/LBP-low. n=346 cases. TTR, time to recurrence; OS, overall survival; AFP, $\alpha$ fetoprotein; HCC, hepatocellular carcinoma; LBP, lipopolysaccharide binding protein.

A

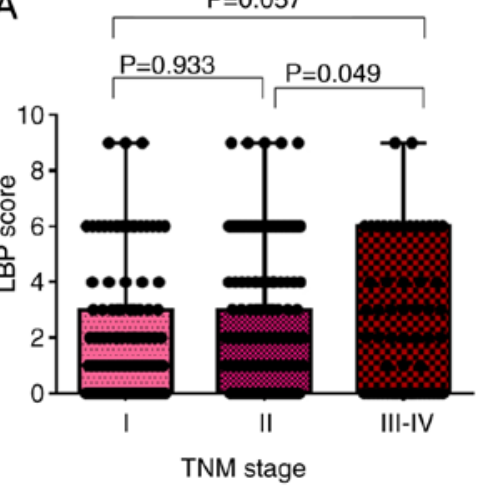

B

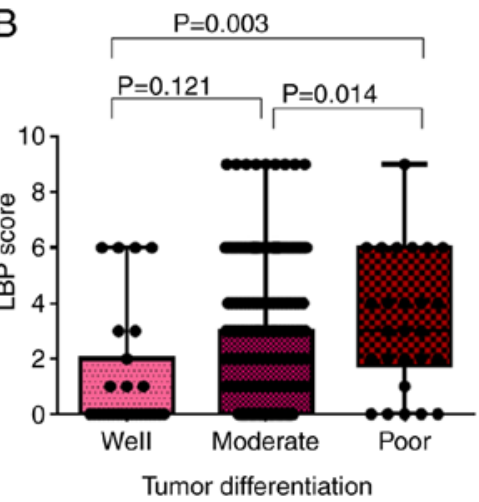

C

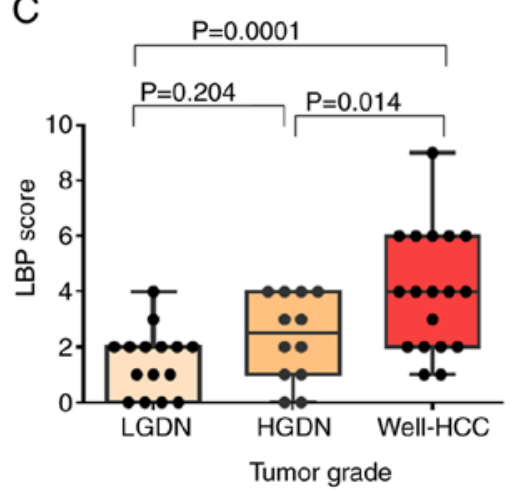

Figure 3.LBP expression levels in different TNM stages, tumor differentiation subtypes and tumor grade. (A) LBP expression was significantly different between stages II and III-IV. (B) LBP expression was significantly increased in poorly differentiated HCC tissues compared with that in well and moderate-differentiated tissues. (C) LBP expression was gradually increased in LGDN, HGDN and well- HCC. One-way ANOVA and least significant difference post-hoc test was used for multiple comparisons. HCC, hepatocellular carcinoma; LBP, lipopolysaccharide binding protein; LGDN, low-grade dysplastic nodules; HGDN, high grade dysplastic nodules; well-HCC; well-differentiated.

tumor differentiation $(\mathrm{P}=0.011)$, but was not associated with sex, age, Hepatitis B surface antigen ( $\mathrm{HBsAg})$, serum AFP, liver cirrhosis, Child-Pugh class, tumor size, tumor number and vascular invasion (all $\mathrm{P}>0.05$; Table II). Based on these $\chi^{2}$ test results, LBP expression was further analyzed in subgroups of TNM stage and tumor grade. Results showed that LBP expression in tumors with TNM stage III-IV were higher compared with that in stage I and II tumors; however, there were no 
Table II. Relationship between LBP expression and clinicopathological features in hepatocellular carcinoma.

\begin{tabular}{|c|c|c|c|}
\hline \multirow[b]{2}{*}{ Variable } & \multicolumn{2}{|c|}{ LBP } & \multirow[b]{2}{*}{ P-value } \\
\hline & Low $(n=233)$ & High $(n=113)$ & \\
\hline Sex & & & 0.160 \\
\hline Male & 200 & 103 & \\
\hline Female & 33 & 10 & \\
\hline Age, years & & & 0.389 \\
\hline$\leq 50$ & 104 & 56 & \\
\hline$>50$ & 129 & 57 & \\
\hline HBsAg & & & 0.640 \\
\hline Negative & 44 & 19 & \\
\hline Positive & 189 & 94 & \\
\hline Serum AFP, ng/ml & & & 0.117 \\
\hline$\leq 20$ & 88 & 33 & \\
\hline$>20$ & 145 & 80 & \\
\hline Liver cirrhosis & & & 0.068 \\
\hline No & 69 & 23 & \\
\hline Yes & 164 & 90 & \\
\hline TNM & & & $0.035^{\mathrm{a}}$ \\
\hline I & 79 & 34 & \\
\hline II & 124 & 52 & \\
\hline III-IV & 30 & 27 & \\
\hline Child-Pugh class & & & 0.452 \\
\hline A & 214 & 101 & \\
\hline $\mathrm{B}$ & 19 & 12 & \\
\hline Tumor size, cm & & & 0.113 \\
\hline$\leq 5$ & 116 & 46 & \\
\hline$>5$ & 117 & 67 & \\
\hline Tumor number & & & 0.073 \\
\hline Single & 187 & 81 & \\
\hline Multiple & 46 & 32 & \\
\hline Tumor differentiation & & & $0.011^{\mathrm{a}}$ \\
\hline Well & 21 & 6 & \\
\hline Moderate & 201 & 92 & \\
\hline Poor & 11 & 15 & \\
\hline Vascular invasion & & & 0.254 \\
\hline No & 91 & 37 & \\
\hline Yes & 142 & 76 & \\
\hline
\end{tabular}

Association between LBP expression level and variables was performed using $\chi^{2}$ analysis. ${ }^{\mathrm{a}} \mathrm{P}<0.05$. HBsAg, Hepatitis B surface antigen; LBP, lipopolysaccharide binding protein; AFP, $\alpha$-fetoprotein.

statistically significant differences between LBP expression in TNM stages I and II and between I and III-IV (Fig. 3A). LBP score was significantly higher in poorly differentiated tumors compared with that in well-differentiated $(\mathrm{P}=0.003)$ and moderately differentiated $(\mathrm{P}=0.014)$ tumors (Fig. 3B). LBP expression was gradually increased in LGDN, HGDN and well-HCC, respectively (HGDN vs. well-HCC, $\mathrm{P}=0.014$;
LGDN vs. well-HCC, $\mathrm{P}=0.0001$; Fig. $3 \mathrm{C}$ ). The representative LBP expression for each stage of TNM, tumor differentiation, and tumor grade is shown in Fig. S2.

In the present study, both LBP expression level and the combination of LBP expression level and serum AFP level were significant prognostic factors for both OS time and TTR (Fig. 2). The prognostic value of LBP in the different status of serum HBsAg and liver cirrhosis was further explored (Fig. S3). The results demonstrated that a high level of LBP might indicate poor prognosis for OS time and TTR in patients who are HBsAg-positive but not for patients who are HBsAg-negative. Similar results were observed in patients with liver cirrhosis (Fig. S4). In addition, in the HBsAg positive group, the OS rate and TTR rate was worse in AFP $(+) / \mathrm{LBP}$ high patients compared with AFP (-)/LBP low patients, whereas no significant differences were observed in the HBsAg negative group (Fig. S5). In the liver cirrhosis and non-cirrhosis group, the OS and TTR rates were worse in AFP (+)/LBP high patients compared with AFP (-)/LBP low patients (Fig. S6). Thus, measurement of both LBP and serum AFP may provide useful prognostic information for patients with HCC.

\section{Discussion}

The primary function of LBP is to act in the recognition, binding, and transport of the LPS $(14,15)$. LBP has previously been associated with the pathogenesis of sepsis (20), and with the prognosis of colorectal carcinoma and renal cell carcinoma $(22,23)$. However, the prognostic role of LBP in HCC and its expression in HCC tumor tissues and peritumor liver tissues has not been reported, to the best of our knowledge. In the present study, LBP expression in peritumor liver tissues was weak overall only nine cases $(11.6 \%$; 9/77) strongly expressed LBP in non-tumor liver tissues (scores of 6 or 9), whereas LBP was strongly expressed in tumor tissues in 24 cases $(31.1 \%, 24 / 77$, scores of 6 or 9). Quantified analysis of LBP expression by western blot analysis further reveals that LBP was overexpressed in tumor tissues compared with peritumor liver tissues (Fig. 1E and F). Furthermore, as shown in Fig. 3B, LBP was highly expressed in poorly differentiated tumors compared with that in well- or moderately differentiated tumors, suggesting high LBP expression might reflect poor differentiation status of HCC.

Hepatocarcinogenesis is a complex and multistep process from preneoplastic lesions, including cirrhosis, LGDNs and HGDN to early- and well-differentiated HCC (32). Therefore, exploring molecular pathogenesis during this multistep process, may assist in understanding how the critical transition happens during HCC initiation at a molecular level. As shown in Fig. 3C, LBP expression levels gradually increased in order of LGDN, HGDN and well-HCC; thus, LBP expression may partially reflect $\mathrm{HCC}$ initiation and progression.

Serum AFP is a common serum biomarker for HCC diagnosis (33). However, due to its low sensitivity and specificity (33-35), Golgi protein 73 (36), vitamin K or antagonist-II (PIVKA-II) (37) were proposed as new serological biomarkers for diagnosing of HCC. Since then, many studies have focused on using AFP and PIVKA-II to predict prognosis $(38,39)$. The prognosis of patients with HCC might also be predicted by molecular classification. Biomarker-based classes of HCC 
would be useful to predict prognosis and design clinical trials for targeted therapy (40). Although progress in clinical predictive biomarkers has been made $(11,25,41)$, the clinical utility of these biomarkers for predicting the prognosis of HCC patients is still unclear.

The present study has some limitations. First, because of its retrospective nature and mono-center design, a multicenter and prospective study should be performed to further evaluate the prognostic value of LBP in HCC. Second, as LBP has been proposed as a diagnostic serum biomarker for ovarian cancer (42), Kawasaki disease (43), and rheumatoid arthritis (44), the diagnostic and prognostic role of serum LBP in patients with HCC should be explored by further research. Finally, the mechanism of LBP overexpression in patients with HCC, and whether LBP could be a therapeutic biomarker for patients with HCC should be evaluated in the future.

In conclusion, the present study is the first to report that LBP is overexpressed in HCC tissues, and that LBP status may indicate the aggressiveness of $\mathrm{HCC}$, and the prognosis of $\mathrm{HCC}$ patients after surgery. Significant differences in the prognosis of patients with HCC stratified by the combination of LBP expression and serum AFP was also found.

\section{Acknowledgements}

The authors would like to thank Dr Cong Wen-Ming and Dr Dong Hui from the Department of Pathology, EHBH for reviewing hematoxylin and eosin staining.

\section{Funding}

The present study was supported by the National Natural Science Foundation of China (grant nos. 81671739 and 81472769).

\section{Availability of data and materials}

The datasets used and/or analyzed during the present study are available from the corresponding author on reasonable request.

\section{Authors' contributions}

NYJ, GZJ and QYC designed and prepared the study and the manuscript. JHJ proposed the study QYC, JHJ, RMJ and GZJ collected and analyzed the data and wrote the first draft of the manuscript. QYC and NYJ performed data analysis. All authors reviewed and approved the manuscript.

\section{Ethics approval and consent to participate}

Each patient provided informed consent for use of these samples and the institutional review board at Eastern Hepatobiliary Surgery Hospital approved the study.

\section{Patient consent for publication}

Not applicable.

\section{Competing interests}

The authors declare that they have no competing interests.

\section{References}

1. Khemlina G, Ikeda S and Kurzrock R: The biology of Hepatocellular carcinoma: Implications for genomic and immune therapies. Mol Cancer 16: 149, 2017.

2. Chen W, Zheng R, Baade PD, Zhang S, Zeng H, Bray F, Jemal A, Yu XQ and He J: Cancer statistics in China, 2015. CA cancer J Clin 66: 115-132, 2016.

3. Tang A, Hallouch O, Chernyak V, Kamaya A and Sirlin CB: Epidemiology of hepatocellular carcinoma: Target population for surveillance and diagnosis. Abdom Radiol (NY) 43: 13-25, 2018.

4. Ziogas DE, Kyrochristos ID, Glantzounis GK, Christodoulou D, Felekouras E and Roukos DH: Primary liver cancer genome sequencing: Translational implications and challenges. Expert Rev Gastroenterol Hepatol 11: 875-883, 2017.

5. Shin J, Yu JH, Jin YJ, Suh YJ, Kim DH, Byun S and Lee JW: Effective therapeutic options for elderly patients with hepatocellular carcinoma: A nationwide cohort study. Medicine (Baltimore) 98: e16150, 2019.

6. Lai EC, Lo CM, Fan ST, Liu CL and Wong J: Postoperative adjuvant chemotherapy after curative resection of hepatocellular carcinoma: A randomized controlled trial. Arch Surg 133: 183-188, 1998.

7. Tung-Ping Poon R, Fan ST and Wong J: Risk factors, prevention, and management of postoperative recurrence after resection of hepatocellular carcinoma. Ann Surg 232: 10-24, 2000.

8. Xia Y, Qiu Y, Li J, Wang K, Xi T, Shen F, Yan Z and Wu M: Adjuvant therapy with capecitabine postpones recurrence of hepatocellular carcinoma after curative resection: A randomized controlled trial. Ann Surg Oncol 17: 3137-3144, 2010.

9. Bai DS, Dai Z, Zhou J, Liu YK, Qiu SJ, Tan CJ, Shi YH, Huang C, Wang Z, He YF and Fan J: Capn4 overexpression underlies tumor invasion and metastasis after liver transplantation for hepatocellular carcinoma. Hepatology 49: 460-470, 2009.

10. Xu YF, Yi Y, Qiu SJ, Gao Q, Li YW, Dai CX, Cai MY, Ju MJ, Zhou J, Zhang BH and Fan J: PEBP1 downregulation is associated to poor prognosis in HCC related to hepatitis B infection. J Hepatol 53: 872-879, 2010.

11. Yang XR, Xu Y, Yu B, Zhou J, Li JC, Qiu SJ, Shi YH, Wang XY, Dai Z, Shi GM, et al: CD24 is a novel predictor for poor prognosis of hepatocellular carcinoma after surgery. Clin Cancer Res 15: 5518-5527, 2009.

12. Cai MY, Tong ZT, Zheng F, Liao YJ, Wang Y, Rao HL, Chen YC, Wu QL, Liu YH, Guan XY, et al: EZH2 protein: A promising immunomarker for the detection of hepatocellular carcinomas in liver needle biopsies. Gut 60: 967-976, 2011.

13. Llovet JM, Bru C and Bruix J: Prognosis of hepatocellular carcinoma: The BCLC staging classification. Semin Liver Dis 19: 329-338, 1999.

14. Schumann RR, Kirschning CJ, Unbehaun A, Aberle HP, Knope HP, Lamping N, Ulevitch RJ and Herrmann F: The lipopolysaccharide-binding protein is a secretory class 1 acute-phase protein whose gene is transcriptionally activated by APRF/STAT/3 and other cytokine-inducible nuclear proteins. Mol Cell Biol 16: 3490-3503, 1996.

15. Schumann RR, Leong SR, Flaggs GW, Gray PW, Wright SD, Mathison JC, Tobias PS and Ulevitch RJ: Structure and function of lipopolysaccharide binding protein. Science 249: 1429-1431, 1990.

16. Yu LX, Yan HX, Liu Q, Yang W, Wu HP, Dong W, Tang L, Lin Y, He YQ, Zou SS, et al: Endotoxin accumulation prevents carcinogen-induced apoptosis and promotes liver tumorigenesis in rodents. Hepatology 52: 1322-1333, 2010.

17. Dapito DH, Mencin A, Gwak GY, Pradere JP, Jang MK, Mederacke I, Caviglia JM, Khiabanian H, Adeyemi A, Bataller R, et al: Promotion of hepatocellular carcinoma by the intestinal microbiota and TLR4. Cancer Cell 21: 504-516, 2012.

18. Darnaud M, Faivre J and Moniaux N: Targeting gut flora to prevent progression of hepatocellular carcinoma. J Hepatol 58: 385-387, 2013.

19. Zhang HL, Yu LX, Yang W, Tang L, Lin Y, Wu H, Zhai B, Tan YX, Shan L, Liu Q, et al: Profound impact of gut homeostasis on chemically-induced pro-tumorigenic inflammation and hepatocarcinogenesis in rats. J Hepatol 57: 803-812, 2012.

20. Malhotra R and Bird MI: L-selectin: A novel receptor for lipopolysaccharide and its potential role in bacterial sepsis. Bioessays 19: 919-923, 1997. 
21. Garcia de Guadiana-Romualdo L, Espanol-Morales I, Cerezuela-Fuentes P, Consuegra-Sánchez L, Hernando-Holgado A, Esteban-Torrella P, Jiménez-Santos E, Viqueira-González M, de Béjar-Almira Á and Albaladejo-Otón MD: Value of lipopolysaccharide binding protein as diagnostic marker of infection in adult cancer patients with febrile neutropenia: Comparison with C-reactive protein, procalcitonin, and interleukin 6. Support Care Cancer 23: 2175-2182, 2015.

22. Chen R, Luo FK, Wang YL, Tang JL and Liu YS: LBP and CD14 polymorphisms correlate with increased colorectal carcinoma risk in Han Chinese. World J Gastroenterol 17: 2326-2331, 2011

23. Kovacs G, Peterfi L, Farkas N, Javorhazy A, Pusztai C and Szanto A: Expression of inflammatory lipopolysaccharide binding protein (LBP) predicts the progression of conventional renal cell carcinoma-a short report. Cell Oncol (Dordr) 40: 651-656, 2017.

24. Bosman FT, Carneiro F, Hruban RH and Theise ND: WHO Classification of tumours of the digestive system. Lyon: IARC Press 3: 205-216, 2010.

25. Jin GZ, Yu WL, Dong H, Zhou WP, Gu YJ, Yu H, Yu H, Lu XY $\mathrm{Xian} \mathrm{ZH}$, Liu YK, et al: SUOX is a promising diagnostic and prognostic biomarker for hepatocellular carcinoma. J Hepatol 59: 510-517, 2013.

26. International Consensus Group for Hepatocellular NeoplasiaThe International Consensus Group for Hepatocellular Neoplasia: Pathologic diagnosis of early hepatocellular carcinoma: A report of the international consensus group for hepatocellular neoplasia. Hepatology 49: 658-664, 2009.

27. Yang GH, Fan J, Xu Y, Qiu SJ, Yang XR, Shi GM, Wu B, Dai Z, Liu YK, Tang ZY and Zhou J: Osteopontin combined with CD44 a novel prognostic biomarker for patients with hepatocellular carcinoma undergoing curative resection. Oncologist 13: 1155-1165, 2008.

28. Tan N, Liu Q, Liu X, Gong Z, Zeng Y, Pan G, Xu Q and He S: Low expression of B-cell-associated protein 31 in human primary hepatocellular carcinoma correlates with poor prognosis. Histopathology 68: 221-229, 2016.

29. Jin H, Wang C, Jin G, Ruan H, Gu D, Wei L, Wang H, Wang N, Arunachalam E, Zhang Y, et al: Regulator of calcineurin 1 gene isoform 4, down-regulated in hepatocellular carcinoma, prevents proliferation, migration, and invasive activity of cancer cells and metastasis of orthotopic tumors by inhibiting nuclear translocation of NFAT1. Gastroenterology 153: 799-811.e733, 2017.

30. Jin GZ, Li Y, Cong WM, Yu H, Dong H, Shu H, Liu XH, Yan GQ, Zhang L, Zhang Y, et al: iTRAQ-2DLC-ESI-MS/MS based identification of a new set of immunohistochemical biomarkers for classification of dysplastic nodules and small hepatocellular carcinoma. J Proteome Res 10: 3418-3428, 2011.

31. Camp RL, Dolled-Filhart M and Rimm DL: X-tile: A new bio-informatics tool for biomarker assessment and outcome-based cut-point optimization. Clin Cancer Res 10: 7252-7259, 2004

32. Kudo M: Multistep human hepatocarcinogenesis: Correlation of imaging with pathology. J Gastroenterol 44 (Suppl) 19: S112-S118, 2009

33. Ertle JM, Heider D, Wichert M, Keller B, Kueper R, Hilgard P, Gerken G and Schlaak JF: A combination of $\alpha$-fetoprotein and des-gamma-carboxy prothrombin is superior in detection of hepatocellular carcinoma. Digestion 87: 121-131, 2013.
34. Morimoto M, Numata K, Nozaki A, Kondo M, Moriya S, Taguri M, Morita S, Konno M, Sugo A, Miyajima E, et al: Novel Lens culinaris agglutinin-reactive fraction of $\alpha$-fetoprotein: A biomarker of hepatocellular carcinoma recurrence in patients with low alpha-fetoprotein concentrations. Int J Clin Oncol 17: 373-379, 2012.

35. Yamamoto K, Imamura H, Matsuyama Y, Hasegawa K, Beck Y, Sugawara Y, Makuuchi M and Kokudo N: Significance of alpha-fetoprotein and des-gamma-carboxy prothrombin in patients with hepatocellular carcinoma undergoing hepatectomy. Ann Surg Oncol 16: 2795-2804, 2009.

36. Marrero JA, Romano PR, Nikolaeva O, Steel L, Mehta A, Fimmel CJ, Comunale MA, D'Amelio A, Lok AS and Block TM: GP73, a resident Golgi glycoprotein, is a novel serum marker for hepatocellular carcinoma. J Hepatol 43: 1007-1012, 2005.

37. Fujiyama S, Morishita T, Sagara K, Sato T, Motohara K and Matsuda I: Clinical evaluation of plasma abnormal prothrombin (PIVKA-II) in patients with hepatocellular carcinoma. Hepatogastroenterology 33: 201-205, 1986.

38. Chon YE, Choi GH, Lee MH, Kim SU, Kim DY, Ahn SH, Kim KS Choi JS, Han KH, Chon CY and Park JY: Combined measurement of preoperative alpha-fetoprotein and des-gamma-carboxy prothrombin predicts recurrence after curative resection in patients with hepatitis-B-related hepatocellular carcinoma. Int J Cancer 131: 2332-2341, 2012.

39. Kang SH, Kim DY, Jeon SM, Ahn SH, Park JY, Kim SU, Kim JK, Lee KS, Chon CY and Han KH: Clinical characteristics and prognosis of hepatocellular carcinoma with different sets of serum AFP and PIVKA-II levels. Eur J Gastroenterol Hepatol 24: 849-856, 2012.

40. Lin Z, Xu SH, Wang HQ, Cai YJ, Ying L, Song M, Wang YQ, Du SJ, Shi KQ and Zhou MT: Prognostic value of DNA repair based stratification of hepatocellular carcinoma. Sci Rep 6: 25999, 2016.

41. Hwang HW, Ha SY, Bang H and Park CK: ATAD2 as a poor prognostic marker for hepatocellular carcinoma after curative resection. Cancer Res Treat 47: 853-861, 2015.

42. Boylan KL, Andersen JD, Anderson LB, Higgins L and Skubitz AP: Quantitative proteomic analysis by iTRAQ(R) for the identification of candidate biomarkers in ovarian cancer serum. Proteome Sci 8: 31, 2010.

43. Kimura Y, Yanagimachi M, Ino Y, Aketagawa M, Matsuo M, Okayama A, Shimizu H, Oba K, Morioka I, Imagawa T, et al: Identification of candidate diagnostic serum biomarkers for Kawasaki disease using proteomic analysis. Sci Rep 7: 43732, 2017.

44. Wen W, Li Y, Cheng Y, He J, Jia R, Li C, Guo J, Sun X and Li Z: Lipopolysaccharide-binding protein is a sensitive disease activity biomarker for rheumatoid arthritis. Clin Exp Rheumatol 36: 233-240, 2018

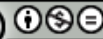

This work is licensed under a Creative Commons Attribution-NonCommercial-NoDerivatives 4.0 International (CC BY-NC-ND 4.0) License. 